\title{
Analysis of Pitch and Duration in Speech Synthesis using PSOLA
}

\author{
Kavita Waghmare \\ Research Student \\ Department of Computer \\ Science and Information \\ Technology \\ Dr. Babasaheb Ambedkar \\ Marathwada University, \\ Aurangabad
}

\author{
Sangramsing Kayte \\ Research Student \\ Department of Computer \\ Science and Information \\ Technology \\ Dr. Babasaheb Ambedkar \\ Marathwada University, \\ Aurangabad
}

\author{
Bharti Gawali \\ Professor \\ Department of Computer \\ Science and Information \\ Technology \\ Dr. Babasaheb Ambedkar \\ Marathwada University, \\ Aurangabad
}

\begin{abstract}
The speech synthesis system is an artificial production of speech with the help of speech synthesizers. It can be achieved using various techniques. During synthesis the smoothing of concatenating points is an important aspect to be studied. This paper attempts to find the effect of pitchmarking process using Time Domain-Pitch Synchronous Overlap and Add (TD-PSOLA) method. The database consists of 60 sentences containing various phones, syllables, phrases which provide prosodic effects in male and female voices. The analysis shows that the pitch -marking process affects the quality of speech in the synthesis process which soothes at concatenation point.
\end{abstract}

\section{Keywords}

Text-to speech (TTS), pitch, duration, PSOLA, pitchmarkings.

\section{INTRODUCTION}

Voice communication has been the primary approach of human communication since it began to evolve at least one hundred thousand years ago. Spoken language is a complex and unique features of the human species. Speech synthesis is the process of automatic generation of speech waveforms, has been under development for several decades [1]. The speech synthesis is also referred as text-to-speech (TTS) synthesis consists of two primary stages. The foremost one is text analysis, where the input text is transliterated into a phonetic or linguistic representation, and the second one is the generation of speech waveforms, where the acoustic output is created from this phonetic and prosodic information[2][3]. These two forms are commonly called as high and low level synthesis. Figure 1 shows a simplified routine of a TTS system. The input text might be a data from a word processor, standard ASCII form, a mobile text-message, or scanned text from any text document. Then the character string is preprocessed, analyzed and transformed into a phonetic representation which is usually a string of phonemes with some additional information for correct intonation, duration, and stress. Speech sound is ultimately generated by the lowlevel synthesizer by the information from high-level one.

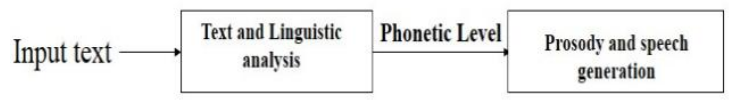

Figure 1.Text-to-Speech (TTS) Synthesis system

\section{TECHNIQUES OF SPEECH SYNTHESIS}

A text-to-Speech (TTS) synthesizer is a computer-based system that should be able to read any text loudly with an input written text. The goal of speech synthesis system is to develop a machine to produce natural sounding voice for conveying the information to the user in a desired accent and language. Synthesized speech can be brought out by various different methods such as articulatory synthesis, formant synthesis, concatenative synthesis and hidden Markov model based synthesis (HMM) [4]. Articulatory synthesis, attempts to model the human speech production system directly. Formant synthesis, which models the pole frequencies of speech signal or transfer function of the vocal tract based on source-filter-model. Concatenative synthesis, uses different length pre-recorded samples derived from natural language.

\subsection{Concatenative Synthesis}

Concatenative synthesis is based on the joining of prerecorded words from the database. It takes small units of speech such as phones, diphones, triphone, syllables, demi syllables, phonemes and words. It is the most elementary method for synthesizing and requires a great number of words in the database. As the number of words that are used in different literatures is extremely large, storing all of those will be quite impossible. To avoid the storage of a large number of words, use of random sentences can serve to surmount this trouble. Equally most of the languages contain 30-40 phonemes at most, and then it would be easy to pull the necessary phonemes according to usage. Only it may lift the issue of discontinuity in the synthesized speech. The choice of units is generally a trade-off between longer and shorter units. Concatenation of words is relatively easy to perform and coarticulation effects within a word are captured in the stored units. This proficiency is normally confined to one speaker. The concatenation synthesis system is dependent on the choice of appropriate units and that joins those units in concert and performs close to signal processing to smooth unit transitions and to match predefined prosodic schemes [5].

There are three types of concatenative synthesis:

i. Unit Selection synthesis

ii. Di-phone synthesis

iii. Domain Based synthesis

\section{i. Unit Selection synthesis}

The unit selection synthesis is a method in which large numbers of pre-recorded words are used in order to get 
synthesized speech. The main purpose of applying this method is to employ a great number of units with varied prosodic and spectral characteristics, which will indeed synthesize more natural-sounding speech than that can be produced by a diminished set of controlled units. It is generally used method. The database contains phones in the desired language. The database should be labeled properly in order to make good quality synthesized speech.

\section{ii. Diphone Synthesis}

The Diphone synthesis method uses a relatively small size database containing all the diphones in the desired language. It consists of a single sample of each set in the desired language. The quantity of diphones in database depends on the phonotactics of the language .This method doesn't work well in the language where there is a lot of inconsequence in the pronunciation rules and in special cases where letters is pronounced differently than in general. It plays well in the languages where there are more consistencies in the pronunciation. The quality of the synthesized speech is comparatively lower than that of unit selection synthesis.

\section{iii. Domain-specific Synthesis}

Domain-specific synthesis consists of phrases and sentences related to a specific application. It can be used in the applications like railway announcement system, weather reports and many more.

\section{iv. Pitch and Duration}

There are various parameters in speech that can be used for analysis purpose. Pitch is one of the most important parameters for speech signal processing, including speech synthesis, automatic speech recognition, speech enhancement. In this paper pitch and duration is focused as it affects the concatenation synthesis process. It can provide smoothing effect on the concatenation points. Thus, it is very important to extract the pitch from the speech accurately. Pitch, in speech, is the relative highness or lowness of the tone as perceived by the ear, which depends on the number of vibrations per second produced by the vocal cords [6]. Pitch is the main acoustic correlate of tone and intonation. The tone is a variation in the pitch which serves to differentiate one word from another word. Tone is usually used for tonal languages. These languages use limited number of pitch contrasts. The domain of the tones is usually the syllable. Intonation is the melodic pattern of an utterance. It is the primarily a matter of variation in the pitch level of the voice, in some languages such as English, where stress and rhythm are also involved. It conveys differences of the expressive meaning. Duration or time characteristics are another important prosodic features that lead to the perceived naturalness of synthetic speech. Variation in duration serves as a clue to the individuality of a spoken language sound. So the primary goal in duration modeling is to model the duration pattern of natural speech, considering various features that affect the pattern. For analyzing changes in pitch and duration PSOLA method has been implemented.

\section{PSOLA (PITCH SYNCHRONOUS OVERLAP AND ADD)}

PSOLA (Pitch Synchronous Overlap and Add) is a digital signal processing technique used for speech processing and more specifically speech synthesis. It can be applied to change the pitch and duration of a speech signal. PSOLA is used for smooth concatenation of pre-recorded speech samples and to provide control for pitch and duration. It is essentially a method used for manipulation of pitch in speech signal. It reads the input signal's pitch and shift it upward or downwards [7] [8].

Basically, there are three versions of PSOLA namely TDPSOLA (Time Domain-PSOLA), FD-PSOLA (Frequency Domain -PSOLA), LP-PSOLA (Linear-Predictive PSOLA). The Time-Domain version, is the most commonly used due to its computational efficiency. The LP-PSOLA is theoretically more appropriate approach for pitch-scale modifications because they provide independent control over the spectral envelope of the synthesis signal and the FD-PSOLA is used only for pitch-scale modifications. TD-PSOLA is commonly used due to its computational efficiency.

Pitch synchronous speech synthesis algorithms require the starting position of the pitch mark for every voiced segment prior to speech synthesis [9]. In Festival speech synthesis platform Linear-Predictive Coding (LPC) resynthesize is used. Pitch-marks are particularly important in prosodic modification algorithms that use a method known as pitch synchronous overlap-and add (PSOLA) to vary the time and pitch scale of a speech signal [10].

There are two major techniques for acquiring pitch-marks, these are:

\section{From an electroglottograph signal, and}

2. Algorithms extracting the pitch-marks directly from the speech signal.

In this work the second algorithm is applied which consists of three steps. The analysis step where the original speech signal is first separated into separate but often overlapping shortterm analysis signals (ST), the alteration of each analysis, signal to synthesis, signal, and the synthesis step where these segments are recombined by means of overlapping-adding. Short term signals $\mathrm{xm}$ (n) are obtained from digital speech waveform xn (n) by multiplying the signal by a sequence of the pitch-synchronous analysis window $\mathrm{hm}(\mathrm{n})$.

$\mathrm{xm}(\mathrm{n})=\mathrm{hm}(\mathrm{tm}-\mathrm{n}) \mathrm{x}(\mathrm{n})$------ equ1

Where $\mathrm{m}$ is an index for the short-time signal. The windows, which are usually Hanning type, are centered on the successive instants tm, called pitch-marks. A pitch-mark is also referred as pitch period is defined as the location of the short-time peak of each pitch pulse in a speech signal, which means the beginning and end of the speech signal. These targets are put at a pitch-synchronous rate in the voiced parts of the signal and at a constant rate on the unvoiced parts. This pitch pulse corresponds to the glottal closure instant (GCI). These marks are set at a pitch-synchronous rate on the voiced parts of the signal and at a constant rate on the unvoiced parts .The used window length is relative to the local pitch period and the window factor is normally from 2 to 4 . The segment recombination in synthesis step is performed after setting a new pitch-mark sequence. Manipulation of the fundamental frequency is attained by varying the time intervals between pitch markers. The alteration of duration is achieved by either repeating or omitting speech signal [11].

\section{SPEECH CORPUS}

The speech database collected for the analysis consists of 60 sample speech signal collected from a male speaker and a female speaker. Each speaker has uttered 30 sentences. These sentences are collected from stories. The database collection 
has been exercised in a recording studio in the afternoon session with a complete noise-free environment. After collecting speech samples, these sentences have undergone through synthesis process. For synthesizing the speech samples Festival framework has been used, which is a platform for research and development with its highly flexible architecture. The technical specification is drawn in a table 1 and the sentences used has been evinced in the table 2 and table 3 with their corresponding labels [12][13][14].
Table 1 shows the technical specification for database creation

\begin{tabular}{|l|l|l|}
\hline Sr.No & \multicolumn{1}{|c|}{ Parameter } & \multicolumn{1}{|c|}{ Specification } \\
\hline 1. & Sampling Frequency & $16 \mathrm{Khz}$ \\
\hline 2. & $\begin{array}{l}\text { Distance from } \\
\text { microphone }\end{array}$ & $10 \mathrm{~cm}$ \\
\hline 3. & Environment & Recording studio \\
\hline 4. & Temperature & 25 \\
\hline 5. & Channel & Single \\
\hline 6. & Gender & Male: 1 Female: 1 \\
\hline
\end{tabular}

Table 2 shows English sentences used for Pitch Estimation in a male voice

\begin{tabular}{|c|c|c|c|}
\hline Sr.No & Sentence & $\begin{array}{l}\text { Label used for } \\
\text { the original } \\
\text { speech file }\end{array}$ & $\begin{array}{l}\text { Label used for the } \\
\text { synthesized speech file }\end{array}$ \\
\hline 1 & Will we ever forget it & R001 & RS001 \\
\hline 2 & If I ever needed a fighter in my life I need one now & R002 & RS002 \\
\hline 3 & $\begin{array}{c}\text { He was a head shorter than his companion, of almost } \\
\text { delicate physique }\end{array}$ & R003 & RS003 \\
\hline 4 & There was a change now & R004 & RS004 \\
\hline 5 & $\begin{array}{l}\text { I followed the line of the proposed railroad, looking } \\
\text { for chances }\end{array}$ & R005 & RS005 \\
\hline 6 & I was about to do this when cooler judgment prevailed & R006 & RS006 \\
\hline 7 & $\begin{array}{l}\text { It occurred to me that there would have to be an } \\
\text { accounting }\end{array}$ & R007 & RS007 \\
\hline 8 & $\begin{array}{l}\text { To my surprise, he began to show actual enthusiasm } \\
\text { in my favor }\end{array}$ & R008 & RS008 \\
\hline 9 & I had faith in them & R009 & RS009 \\
\hline 10 & She turned in at the hotel & R010 & RS010 \\
\hline 11 & I was the only one who remained sitting & R011 & RS011 \\
\hline 12 & We'll have to watch our chances & R012 & RS012 \\
\hline 13 & The ship should be in within a week or ten days & R013 & RS013 \\
\hline 14 & I suppose you wonder why she is coming up here & R014 & RS014 \\
\hline 15 & He moved away as quietly as he had come & R015 & RS015 \\
\hline 16 & It was a curious coincidence & R016 & RS016 \\
\hline 17 & $\begin{array}{l}\text { Suddenly his fingers closed tightly over the } \\
\text { handkerchief }\end{array}$ & R017 & RS017 \\
\hline 18 & There was nothing on the rock & R018 & RS018 \\
\hline 19 & There has been a change, she interrupted him & R019 & RS019 \\
\hline 20 & Each day she became a more vital part of him & R020 & RS020 \\
\hline 21 & It was a temptation, but he resisted it & R021 & RS021 \\
\hline 22 & Does that look good & R022 & RS022 \\
\hline 23 & Very early in my life, I separated from my mother & R023 & RS023 \\
\hline 24 & This is no place for you & R024 & RS024 \\
\hline
\end{tabular}




\begin{tabular}{|c|c|c|c|}
\hline 25 & They only lifted seven hundred and fifty & R025 & RS025 \\
\hline 26 & I'll go over tomorrow afternoon & R026 & RS027 \\
\hline 27 & But it won't continue, she said with easy confidence & R027 & RS028 \\
\hline 28 & The night was calm and snowy & R028 & RS029 \\
\hline 29 & He had comparatively no advantages at first & R029 & RS030 \\
\hline 30 & Without them he could not run his empire & R030 & \\
\hline
\end{tabular}

Table 3 shows English sentences used for Pitch Estimation in female voice

\begin{tabular}{|c|c|c|c|}
\hline Sr.no & Sentence & $\begin{array}{c}\text { Labels for original } \\
\text { speech signal }\end{array}$ & $\begin{array}{l}\text { Label synthesized } \\
\text { speech signal }\end{array}$ \\
\hline 1 & I can see that knife now & B001 & BS001 \\
\hline 2 & They robbed me a few years later & B002 & BS002 \\
\hline 3 & I was completely lost in my work & B003 & BS003 \\
\hline 4 & He caught himself with a jerk & B004 & BS004 \\
\hline 5 & It won't be for sale & B005 & BS005 \\
\hline 6 & $\begin{array}{l}\text { She was even more beautiful than when I saw } \\
\text { her, before }\end{array}$ & B006 & BS006 \\
\hline 7 & There was no answer from the other side & B007 & BS007 \\
\hline 8 & $\begin{array}{l}\text { Tomorrow it will be strong enough for you to } \\
\text { stand upon }\end{array}$ & B008 & BS008 \\
\hline 9 & $\begin{array}{c}\text { You were going to leave after you saw me on } \\
\text { the rock }\end{array}$ & B009 & BS009 \\
\hline 10 & I want to die in it & B010 & BS010 \\
\hline 11 & The journey was continued at dawn & B011 & BS011 \\
\hline 12 & She saw the answer in his face & B012 & BS012 \\
\hline 13 & In it was the joy of life & B013 & BS013 \\
\hline 14 & That is the strange part of it & B014 & BS014 \\
\hline 15 & Then he shouted, Shut up & B015 & BS015 \\
\hline 16 & Also, I want information & B016 & BS016 \\
\hline 17 & Let them go out and eat with my boys & B017 & BS017 \\
\hline 18 & You were destroying my life & B018 & BS018 \\
\hline 19 & You read the quotations in today's paper & B019 & BS019 \\
\hline 20 & Let us talk it over and find a way out & B020 & BS020 \\
\hline 21 & It is a good property, and worth more than that & B021 & BS021 \\
\hline 22 & Again he had done the big thing & B022 & BS022 \\
\hline 23 & Daylight was tired, profoundly tired & B023 & BS023 \\
\hline 24 & Please do not think that I already know it all & B024 & BS024 \\
\hline 25 & You have all the advantage & B025 & $\mathrm{BS} 025$ \\
\hline 26 & They are not biologists nor sociologists & B026 & BS026 \\
\hline 27 & I want to know how all this is possible & B027 & BS027 \\
\hline 28 & You have all the advantage & B028 & BS028 \\
\hline 29 & And as never before, he was ready to obey & B029 & BS029 \\
\hline 30 & My age, in years, is twenty two & B030 & BS030 \\
\hline
\end{tabular}

\section{STATISTICAL ANALYSIS}

The pitch values contain the speaker specific information. The pitch variation carries the intonation signal associated with rhythms of speech, speaking manner, emotions and accent. The gender is one of the factor which convey a part in characterization of vocal tract. Randomly, the average pitch for female is about $200 \mathrm{~Hz}$ and for male it is about $110 \mathrm{~Hz}$.Pitch variation is often correlated with loudness and 
lowness in speech samples. The experimentation is done by counting on the prosodic features as pitch, duration, frequency, fundamental frequency values for a male and a female speaker

These values are calculated using Computerized Speech Lab (CSL). For Pitch analysis, statistical techniques such as mean, standard deviation, root mean square (rms), geometric mean are used. It is clearly visible in table number $4,5,6, \& 7$ where the values of minimum pitch and the maximum can be seen and altered in order to get good quality speech. Due to the alteration in the pitch values the duration is also altered in some of the speech samples. According to PSOLA algorithm, the values of mean frequency and fundamental frequency F0 is either increased or decreased according the necessity. From the table it can also be seen that the frequency is reduced while mean period is increased and vice versa. The standard deviation indicates the dispersion of pitch values from its mean value whereas median shows the central values of the respective speech samples. Root mean square (RMS) is a useful measure when the data are negative and positive such as sinusoids. It is also a quadratic measure and calculated using values of the samples. A geometric mean is often used when comparing different items finding a single "figure of merit" for these items when each item has multiple properties that have different numeric ranges [12][13][14].

Table 4 shows the values of various statistical measures used in the pitch analysis for Female subject for Original Speech Sample

\begin{tabular}{|c|c|c|c|c|c|c|c|c|c|c|}
\hline Label & $\begin{array}{l}\text { End of } \\
\text { Analysi } \\
\text { S }\end{array}$ & $\begin{array}{l}\text { Min } \\
\text { pitch }\end{array}$ & $\begin{array}{l}\text { Max } \\
\text { pitch }\end{array}$ & $\begin{array}{l}\text { Mean } \\
\text { Frequen } \\
\text { cy }\end{array}$ & $\begin{array}{l}\text { Mean } \\
\text { FO }(\mathbf{H z})\end{array}$ & $\begin{array}{l}\text { Mean } \\
\text { Perio } \\
\text { d } \\
(\text { msec }) \\
\end{array}$ & $\begin{array}{l}\text { Standar } \\
\text { d } \\
\text { Deviatio } \\
\text { n }(\mathbf{H z}) \\
\end{array}$ & $\begin{array}{l}\text { Media } \\
\text { n } \\
\text { Pitch } \\
(\mathbf{H z}) \\
\end{array}$ & $\begin{array}{l}\text { Root } \\
\text { Mean } \\
\text { square } \\
(\mathbf{H z}) \\
\end{array}$ & $\begin{array}{l}\text { Geometr } \\
\text { ic } \\
\text { Mean }(H \\
\text { z) }\end{array}$ \\
\hline B001 & 1.77 & 135.54 & 306.62 & 221.35 & 211.44 & 4.73 & 46.19 & 216.65 & 226.03 & 216.46 \\
\hline B002 & 2.45 & 129.65 & 293.82 & 200.8 & 213.31 & 4.69 & 39.21 & 219.01 & 224.22 & 217.17 \\
\hline B003 & 2.31 & 146 & 326.94 & 250.85 & 243.77 & 4.1 & 39.41 & 254.49 & 253.89 & 247.49 \\
\hline B004 & 2.19 & 131.03 & 310.48 & 225.56 & 216.68 & 4.62 & 43.04 & 224.11 & 229.56 & 221.26 \\
\hline B005 & 1.80 & 149.09 & 295.45 & 236.44 & 230.89 & 4.33 & 34.63 & 239.69 & 238.91 & 233.77 \\
\hline B006 & 4.65 & 115.86 & 323.09 & 221.98 & 215.37 & 4.64 & 35.85 & 224 & 224.83 & 218.86 \\
\hline B007 & 2.75 & 125.54 & 285.08 & 216.56 & 208.03 & 4.81 & 39.4 & 225 & 220.08 & 212.56 \\
\hline B008 & 3.56 & 130.13 & 305.94 & 207.35 & 201.68 & 4.96 & 33.61 & 205.43 & 210.03 & 204.57 \\
\hline B009 & 4.10 & 121.29 & 294.09 & 225.42 & 220.99 & 4.53 & 29.97 & 226.35 & 227.39 & 223.31 \\
\hline B010 & 1.68 & 116.6 & 310.93 & 209.8 & 204.14 & 4.9 & 33.09 & 212.86 & 212.34 & 207.09 \\
\hline B011 & 2.64 & 100.18 & 285.36 & 213.25 & 203.86 & 4.91 & 40.65 & 223.3 & 217.05 & 208.89 \\
\hline B012 & 2.71 & 103.57 & 304.38 & 225.94 & 219.2 & 4.56 & 34.03 & 228.46 & 228.45 & 222.93 \\
\hline B013 & 2.68 & 92.59 & 272.84 & 201.22 & 191.99 & 5.21 & 37.48 & 205.72 & 204.64 & 197.09 \\
\hline B014 & 2.10 & 155.79 & 289.11 & 219.9 & 215.23 & 4.65 & 32.32 & 215.9 & 222.21 & 217.56 \\
\hline B015 & 2.06 & 121.72 & 289.47 & 217.04 & 210.45 & 4.75 & 35.96 & 218.58 & 219.94 & 213.88 \\
\hline B016 & 2.35 & 122.56 & 270.84 & 212.08 & 207.78 & 4.81 & 28.41 & 208.18 & 213.95 & 210.04 \\
\hline B017 & 3.18 & 95.77 & 288.73 & 206.42 & 198.23 & 5.04 & 38.48 & 202.71 & 209.93 & 202.55 \\
\hline B018 & 2.23 & 87.28 & 296.5 & 215.28 & 205.5 & 4.87 & 40.05 & 214.04 & 218.93 & 210.93 \\
\hline B019 & 3.55 & 72.87 & 279.23 & 211.87 & 203.95 & 4.9 & 31.74 & 212.94 & 214.21 & 208.69 \\
\hline B020 & 3.45 & 102.01 & 240.97 & 199.33 & 195.37 & 5.12 & 24.22 & 201.22 & 200.78 & 197.57 \\
\hline B021 & 3.94 & 132.89 & 278.78 & 205.11 & 200.41 & 4.99 & 30.43 & 204.57 & 207.34 & 202.8 \\
\hline B022 & 2.48 & 142.97 & 304.3 & 215.27 & 208.74 & 4.79 & 36.8 & 219.73 & 218.36 & 212.06 \\
\hline B023 & 3.34 & 134.85 & 300.74 & 226.59 & 221.36 & 4.52 & 32.87 & 227.06 & 228.93 & 224.07 \\
\hline B024 & 4.08 & 143.85 & 320.99 & 233.31 & 227.94 & 4.39 & 34.96 & 230.44 & 235.89 & 230.67 \\
\hline B025 & 3.55 & 143.5 & 309.9 & 221.19 & 216.7 & 4.61 & 31.47 & 221.14 & 235.89 & 218.96 \\
\hline B026 & 2.96 & 156.15 & 280.04 & 213.4 & 210.75 & 4.74 & 24.41 & 210.37 & 223.4 & 212.06 \\
\hline B027 & 4.20 & 103.44 & 372.71 & 218.27 & 212.15 & 4.71 & 33.68 & 221.65 & 214.77 & 215.42 \\
\hline B028 & 2.31 & 106.48 & 298.51 & 217.19 & 208.94 & 4.79 & 39.13 & 225.11 & 220.83 & 213.32 \\
\hline B029 & 4.12 & 145.74 & 288.12 & 215.09 & 211.55 & 4.73 & 27.05 & 214.96 & 216.77 & 213.35 \\
\hline B030 & 2.33 & 129.03 & 290.84 & 228.29 & 222.8 & 4.49 & 32.71 & 235.25 & 230.59 & 225.72 \\
\hline
\end{tabular}


Table 5 shows the values of various statistical measures used for the pitch analysis for Female subject for Synthesized Speech Sample

\begin{tabular}{|c|c|c|c|c|c|c|c|c|c|c|}
\hline Label & $\begin{array}{c}\text { End of } \\
\text { Analys } \\
\text { is }\end{array}$ & $\begin{array}{c}\text { Min } \\
\text { pitch }\end{array}$ & $\begin{array}{l}\text { Max } \\
\text { pitch }\end{array}$ & $\begin{array}{c}\text { Mean } \\
\text { Freque } \\
\text { ncy }\end{array}$ & $\begin{array}{c}\text { Mean } \\
\text { F0(Hz) } \\
\end{array}$ & $\begin{array}{l}\text { Mean } \\
\text { Period } \\
(\mathrm{msec})\end{array}$ & $\begin{array}{c}\text { Standar } \\
\text { d } \\
\text { Deviatio } \\
\text { n (Hz) } \\
\end{array}$ & $\begin{array}{c}\text { Median } \\
\text { Pitch } \\
(\mathbf{H z}) \\
\end{array}$ & $\begin{array}{c}\text { Root } \\
\text { Mean } \\
\text { Square } \\
(\mathbf{H z}) \\
\end{array}$ & $\begin{array}{c}\text { Geometr } \\
\text { ic } \\
\text { Mean }(H \\
\text { z) } \\
\end{array}$ \\
\hline BS001 & 3.78 & 126.95 & 255.9 & 210.07 & 206.54 & 4.84 & 24.29 & 214.71 & 211.46 & 208.45 \\
\hline BS002 & 2.45 & 137.5 & 302.55 & 224.74 & 217.75 & 4.59 & 38.71 & 223.21 & 228.01 & 221.31 \\
\hline BS003 & 2.29 & 143.6 & 328.59 & 228.17 & 217.69 & 4.59 & 46.26 & 243.23 & 232.75 & 223.12 \\
\hline BS004 & 1.53 & 126.92 & 299.96 & 231.36 & $223 . .56$ & 4.47 & 39.5 & 230.92 & 234.63 & 227.69 \\
\hline BS005 & 1.53 & 123.92 & 299.96 & 231.36 & 223.56 & 4.47 & 39.5 & 230.92 & 234.63 & 227.69 \\
\hline BS006 & 4.21 & 85.81 & 318.45 & 224.14 & 217.22 & 4.6 & 34.87 & 220.71 & 226.82 & 221.07 \\
\hline BS007 & 2.75 & 125.54 & 285.08 & 216.56 & 208.03 & 4.81 & 39.4 & 225 & 220.08 & 212.56 \\
\hline BS008 & 3.76 & 130.6 & 312 & 205.64 & 200.16 & 5 & 32.68 & 205.74 & 208.2 & 202.97 \\
\hline BS009 & 4.08 & 122.51 & 287.04 & 218.82 & 213.64 & 4.68 & 30.91 & 222.47 & 220.98 & 216 \\
\hline BS010 & 1.57 & 161.83 & 246.95 & 211.84 & 210.15 & 4.76 & 18.53 & 214.43 & 212.63 & 211.01 \\
\hline BS011 & 2.54 & 88.37 & 282.28 & 209.78 & 197.13 & 5.07 & 44.87 & 224.43 & 214.48 & 204.08 \\
\hline BS012 & 2.69 & 126.56 & 287.62 & 221.68 & 216.66 & 4.62 & 30.74 & 221.68 & 223.77 & 219.33 \\
\hline BS013 & 2.32 & 92.06 & 271.04 & 201.83 & 192.83 & 5.19 & 37.19 & 206.18 & 205.18 & 197.8 \\
\hline BS014 & 2.02 & 137.56 & 304.85 & 221.51 & 215.86 & 4.63 & 34.9 & 218.72 & 224.19 & 218.73 \\
\hline BS015 & 2.06 & 138.8 & 288.22 & 221.81 & 217.06 & 4.61 & 31.57 & 220.32 & 224 & 219.5 \\
\hline BS016 & 2.33 & 123.1 & 273.3 & 210.58 & 205.88 & 4.86 & 29.66 & 208.37 & 212.63 & 208.35 \\
\hline BS017 & 3.15 & 85.42 & 293.75 & 203.21 & 191.78 & 5.21 & 43.09 & 201.18 & 207.69 & 198.02 \\
\hline BS018 & 2.21 & 81.77 & 297.06 & 213.98 & 203.72 & 4.91 & 40.42 & 217.09 & 217.71 & 209.44 \\
\hline BS019 & 3.53 & 73.19 & 292.13 & 209.13 & 201.81 & 4.96 & 31.8 & 210.61 & 211.75 & 206.29 \\
\hline BS020 & 3.45 & 102.01 & 240.97 & 199.33 & 195.37 & 5.12 & 24.22 & 201.22 & 200.78 & 197.57 \\
\hline BS021 & 3.94 & 132.89 & 278.78 & 205.11 & 200.41 & 4.99 & 30.43 & 204.57 & 207.34 & 202.8 \\
\hline BS022 & 2.48 & 142.97 & 304.3 & 215.27 & 208.74 & 4.79 & 36.8 & 219.73 & 218.36 & 212.06 \\
\hline BS023 & 3.15 & 103.13 & 299.06 & 222.04 & 214.04 & 4.67 & 38.67 & 224.04 & 225.35 & 218.31 \\
\hline BS024 & 3.93 & 133.49 & 333.64 & 229.3 & 220.95 & 4.53 & 41.32 & 231.5 & 232.96 & 225.31 \\
\hline BS025 & 3.52 & 143.54 & 312.15 & 220.78 & 216.34 & 4.62 & 31.57 & 217.4 & 223.01 & 218.56 \\
\hline BS026 & 2.96 & 156.15 & 280.04 & 213.4 & 210.75 & 4.74 & 24.41 & 210.37 & 214.77 & 212.06 \\
\hline BS027 & 3.73 & 80.63 & 314.7 & 222.28 & 216.43 & 4.62 & 31.98 & 223.17 & 224.55 & 219.67 \\
\hline BS028 & 2.29 & 98.78 & 321.3 & 216.18 & 206.24 & 4.85 & 41.57 & 226.36 & 220.08 & 211.64 \\
\hline BS029 & 3.77 & 153.66 & 285.34 & 214.77 & 212.41 & 4.71 & 22.6 & 213.61 & 215.94 & 213.59 \\
\hline BS030 & 2.07 & 126.98 & 287.75 & 228.14 & 221.5 & 4.51 & 36.28 & 236.61 & 230.96 & 225 \\
\hline
\end{tabular}

The table number 6 and 7 shows the total time of analysis, the minimum and the maximum value of pitch, mean value of frequency, mean value of the fundamental frequency, mean period, the standard deviation of the pitch values, the median value of pitch, root mean square value of pitch and the geometric mean of the male subject of the original speech sample and the synthesized one [12][13][14]. 
Table 6 shows the values of various statistical measures used for the pitch analysis for Male subject for Original Speech Sample

\begin{tabular}{|c|c|c|c|c|c|c|c|c|c|c|}
\hline Label & $\begin{array}{c}\text { End of } \\
\text { Analysi } \\
\quad \mathrm{S}\end{array}$ & $\begin{array}{l}\text { Min } \\
\text { pitch }\end{array}$ & $\begin{array}{l}\text { Max } \\
\text { pitch }\end{array}$ & $\begin{array}{c}\text { Mean } \\
\text { Frequen } \\
\text { cy }\end{array}$ & $\begin{array}{c}\text { Mean } \\
\text { F0(Hz } \\
\quad)\end{array}$ & $\begin{array}{c}\text { Mean } \\
\text { Perio } \\
\text { d } \\
(\mathrm{msec})\end{array}$ & $\begin{array}{c}\text { Standar } \\
\text { d } \\
\text { Deviatio } \\
\text { n }(\mathbf{H z})\end{array}$ & $\begin{array}{c}\text { Median } \\
\text { Pitch } \\
(\mathbf{H z})\end{array}$ & $\begin{array}{c}\text { Root } \\
\text { Mean } \\
\text { Square } \\
\text { (Hz) }\end{array}$ & $\begin{array}{c}\text { Geometr } \\
\text { ic } \\
\text { Mean }(H \\
\text { z) }\end{array}$ \\
\hline R001 & 1.83 & 100.48 & 164.77 & 132.92 & 130.97 & 7.54 & 16.4 & 130.32 & 133.9 & 131.93 \\
\hline R002 & 3.47 & 93.49 & 200.74 & 128.62 & 126.39 & 7.87 & 17.65 & 126.26 & 129.81 & 127.48 \\
\hline R003 & 4.06 & 93.9 & 178.63 & 129.4 & 127.12 & 7.84 & 17.21 & 126.81 & 130.53 & 128.26 \\
\hline R004 & 1.62 & 100.31 & 148.6 & 124.64 & 122.8 & 8.15 & 15.07 & 126.09 & 125.53 & 123.73 \\
\hline R005 & 4.21 & 97.09 & 196.29 & 125.89 & 123.87 & 8.09 & 16.44 & 124.07 & 126.95 & 124.86 \\
\hline R006 & 3.35 & 91.68 & 266.16 & 130.43 & 126.46 & 7.92 & 27.38 & 123.28 & 133.25 & 128.23 \\
\hline R007 & 2.81 & 102.1 & 211.86 & 131.29 & 129.24 & 7.68 & 17.59 & 128.49 & 132.22 & 130.22 \\
\hline R008 & 3.96 & 94.08 & 175.41 & 128.03 & 126.45 & 7.84 & 14.48 & 125.89 & 128.84 & 127.23 \\
\hline R009 & 1.54 & 89.19 & 150.97 & 122.08 & 119.12 & 8.39 & 18.59 & 125.18 & 123.46 & 120.63 \\
\hline R010 & 2.04 & 98.32 & 263.96 & 142.32 & 136.4 & 7.33 & 34.13 & 138.14 & 146.29 & 139.07 \\
\hline R011 & 2.52 & 85.62 & 182.49 & 132.93 & 130.53 & 7.66 & 17.83 & 129.01 & 134.11 & 131.74 \\
\hline R012 & 2.26 & 80.35 & 160.23 & 130.65 & 128.62 & 7.77 & 14.93 & 131.91 & 131.49 & 129.7 \\
\hline R013 & 3.12 & 78.15 & 169.69 & 124.25 & 121.84 & 8.21 & 16.86 & 125.71 & 125.37 & 123.08 \\
\hline R014 & 3.12 & 92.09 & 251.31 & 132.94 & 130.26 & 7.68 & 21.58 & 127.86 & 134.66 & 131.5 \\
\hline R015 & 2.79 & 83.62 & 172.62 & 133.75 & 131.06 & 7.63 & 18.2 & 136.26 & 134.97 & 132.45 \\
\hline R016 & 1.93 & 75.73 & 200.95 & 139.66 & 134.27 & 7.45 & 25.8 & 140.82 & 141.82 & 137.1 \\
\hline R017 & 3.52 & 78.34 & 162.77 & 129.41 & 126.75 & 7.89 & 17.69 & 130.68 & 130.6 & 128.13 \\
\hline R018 & 2.38 & 102.26 & 171.71 & 131.42 & 129.71 & 7.71 & 15.41 & 129.33 & 132.3 & 130.55 \\
\hline R019 & 3.00 & 105.36 & 161.17 & 134.46 & 133.58 & 7.49 & 10.91 & 132.96 & 134.9 & 134.02 \\
\hline R020 & 2.56 & 73.62 & 257.96 & 131.86 & 127.89 & 7.82 & 24.71 & 132.6 & 134.13 & 129.83 \\
\hline R021 & 1.26 & 80.41 & 151.82 & 129.32 & 126.62 & 7.9 & 16.65 & 134.75 & 130.36 & 128.08 \\
\hline R022 & 2.98 & 93.49 & 230.14 & 140.61 & 137.15 & 7.29 & 22.85 & 142.38 & 142.44 & 138.85 \\
\hline R023 & 3.12 & 98.96 & 176.27 & 139.88 & 137.97 & 7.25 & 16.11 & 138.99 & 140.79 & 138.93 \\
\hline R024 & 1.82 & 94.8 & 285.32 & 133.87 & 129.08 & 7.75 & 31.66 & 130.8 & 137.5 & 131.18 \\
\hline R025 & 2.59 & 107.33 & 256.43 & 139.05 & 136.62 & 7.32 & 21.99 & 134.13 & 140.76 & 137.71 \\
\hline R026 & 2.17 & 82.87 & 170.37 & 131.71 & 128.13 & 7.8 & 20.05 & 132.72 & 133.2 & 130.03 \\
\hline R027 & 3.76 & 88.52 & 172.97 & 135.42 & 133.17 & 7.51 & 16.76 & 135.52 & 136.44 & 134.33 \\
\hline R028 & 2.15 & 81.37 & 169.36 & 130.9 & 127.06 & 7.87 & 20.94 & 131.28 & 132.55 & 129.08 \\
\hline R029 & 2.13 & 102.94 & 26924 & 146.79 & 142.04 & 7.04 & 29.52 & 141.34 & 149.69 & 144.27 \\
\hline R030 & 4.22 & 98.13 & 251.4 & 142.69 & 139.87 & 7.15 & 22.56 & 140.2 & 144.45 & 141.19 \\
\hline
\end{tabular}


Table 7 shows the values of various statistical measures used for the pitch analysis for Female subject for Synthesized Speech Sample

\begin{tabular}{|c|c|c|c|c|c|c|c|c|c|c|}
\hline Label & $\begin{array}{c}\text { End of } \\
\text { Analysi } \\
\text { s } \\
\end{array}$ & $\begin{array}{l}\text { Min } \\
\text { pitch }\end{array}$ & $\begin{array}{l}\text { Max } \\
\text { pitch }\end{array}$ & $\begin{array}{c}\text { Mean } \\
\text { Frequen } \\
\text { cy } \\
\end{array}$ & $\begin{array}{c}\text { Mean } \\
\text { Fo(Hz } \\
\quad) \\
\end{array}$ & $\begin{array}{c}\text { Mean } \\
\text { Perio } \\
\text { d } \\
(\mathrm{msec}) \\
\end{array}$ & $\begin{array}{c}\text { Standar } \\
\text { d } \\
\text { Deviatio } \\
\text { n (Hz) } \\
\end{array}$ & $\begin{array}{c}\text { Media } \\
\text { n } \\
\text { Pitch } \\
(\mathbf{H z}) \\
\end{array}$ & $\begin{array}{c}\text { Root } \\
\text { Mean } \\
\text { Squar } \\
\text { e } \\
(\mathbf{H z}) \\
\end{array}$ & $\begin{array}{c}\text { Geometr } \\
\text { ic } \\
\text { Mean }(H \\
\text { z) } \\
\end{array}$ \\
\hline RS001 & 1.81 & 92.93 & 203.8 & 135.9 & 132.58 & 7.54 & 22.27 & 130.78 & 137.68 & 134.2 \\
\hline RS002 & 3.45 & 99.59 & 274.17 & 130.49 & 127.11 & 7.87 & 24.89 & 125 & 132.83 & 128..64 \\
\hline RSO03 & 4.05 & 94.73 & 178.03 & 124.67 & 127.61 & 7.84 & 16.52 & 127.4 & 130.76 & 128.67 \\
\hline RS004 & 1.59 & 98.93 & 157.63 & 124.67 & 122.75 & 8.15 & 15.5 & 123.99 & 125.61 & 123.71 \\
\hline RS005 & 4.20 & 92.52 & 161.13 & 125.48 & 123.66 & 8.09 & 15.26 & 123.6 & 126.4 & 124.57 \\
\hline RS006 & 3.33 & 91.77 & 269.53 & 130.68 & 126.27 & 7.92 & 29.26 & 122.83 & 133.89 & 128.22 \\
\hline RS007 & 2.80 & 102.51 & 245.37 & 132.8 & 130.21 & 7.68 & 20.87 & 130.45 & 134.41 & 131.42 \\
\hline RS008 & 4.07 & 92.99 & 164.62 & 129.34 & 127.55 & 7.84 & 15.32 & 127.64 & 130.24 & 128.44 \\
\hline RS009 & 1.52 & 80.77 & 151.49 & 122.05 & 118.5 & 8.44 & 19.67 & 127.38 & 123.59 & 120.35 \\
\hline RS010 & 1.86 & 84.79 & 185.86 & 130.73 & 126.83 & 7.88 & 22.12 & 133.35 & 132.56 & 128.82 \\
\hline RS011 & 2.50 & 85.88 & 273.35 & 134.9 & 130.98 & 7.63 & 26.25 & 129.5 & 137.4 & 132.82 \\
\hline RS012 & 2.24 & 92.02 & 233.27 & 136.68 & 133.28 & 7.5 & 24.42 & 133.45 & 138.81 & 134.87 \\
\hline RS013 & 3.10 & 78.8 & 178.87 & 124.51 & 122.13 & 8.19 & 17.25 & 125.45 & 125.68 & 123.33 \\
\hline RS014 & 3.10 & 109.86 & 160.44 & 131.04 & 129.93 & 7.7 & 12.44 & 127.3 & 131.63 & 130.48 \\
\hline RS015 & 2.77 & 98.38 & 177.05 & 135.42 & 133.47 & 7.49 & 16.41 & 134.92 & 136.4 & 134.44 \\
\hline RS016 & 3.35 & 88.45 & 182.49 & 137.17 & 134.84 & 7.42 & 17.33 & 137.29 & 138.25 & 136.04 \\
\hline RS017 & 1.89 & 86.49 & 186.05 & 142.59 & 139.03 & 7.19 & 21.39 & 141.2 & 144.15 & 140.89 \\
\hline RS018 & 3.50 & 78.22 & 338.41 & 133.34 & 128.38 & 7.79 & 32.77 & 131.23 & 137.27 & 130.57 \\
\hline RS019 & 1.77 & 100.63 & 283.25 & 139.04 & 134.28 & 7.45 & 32.17 & 131.96 & 142.64 & 136.35 \\
\hline $\mathrm{RS} 020$ & 2.57 & 82.33 & 210.66 & 133.85 & 130.25 & 7.68 & 22.15 & 132.9 & 135.64 & 132.05 \\
\hline RS021 & 2.97 & 105.67 & 161.33 & 135.53 & 134.66 & 7.43 & 10.97 & 132.68 & 135.97 & 135.1 \\
\hline $\mathrm{RS} 022$ & 2.56 & 90.51 & 160.62 & 129.96 & 127.67 & 7.83 & 16.83 & 132.14 & 131.03 & 128.84 \\
\hline RS023 & 1.24 & 74.37 & 259.59 & 135.29 & 129.08 & 7.75 & 30.71 & 135.21 & 138.65 & 132.18 \\
\hline RS024 & 3.05 & 70.8 & 220.68 & 140.47 & 136.22 & 7.34 & 23.55 & 142.56 & 142.41 & 138.48 \\
\hline RS025 & 2.95 & 104.64 & 176.15 & 141.69 & 139.95 & 7.15 & 15.59 & 140.27 & 142.54 & 140.83 \\
\hline RS026 & 1.80 & 96.08 & 150.38 & 128.59 & 126.91 & 7.88 & 14.26 & 130.74 & 129.36 & 127.77 \\
\hline RS027 & 2.63 & 103.73 & 324.19 & 142.06 & 138.23 & 7.23 & 31.2 & 133.47 & 145.4 & 139.82 \\
\hline $\mathrm{RS} 028$ & 2.15 & 81.37 & 169.36 & 130.9 & 127.06 & 7.87 & 20.94 & 131.28 & 132.55 & 129.08 \\
\hline RS029 & 1.88 & 102.34 & 240.9 & 140.69 & 137.96 & 7.25 & 22.05 & 139.46 & 142.38 & 139.24 \\
\hline RS030 & 2.92 & 100.69 & 196.48 & 147.15 & 143.84 & 6.95 & 22.04 & 146.34 & 148.78 & 145.5 \\
\hline
\end{tabular}

\section{CONCLUSION}

From the analysis, it is found that pitch and duration affects the synthesis process. In the table $4,5,6$ and 7 the significance difference can be seen in the original speech and the synthesized speech. It is found that some values of pitch are raised and some are lowered in order to improve the quality of speech, which is useful in smoothly concatenating the words. A good quality speech can in turn provide good quality synthesized speech. Thus it can be said that pitch marking process is really very essential to get good quality synthesized speech.

\section{REFERENCES}

[1] Archana Balyan, S. S. Agrawal, Amita Dev,"Speech Synthesis: A review", IJERT, vol.2 Issue 6, June 20013.

[2] A. Indumathi, Dr. E. Chandra," Survey on speech synthesis", Signal Processing: An International Journal (SPIJ), Volume (6): Issue (5): 2012.

[3] Shruti Gupta, Prateek Kumar, "Comparative study of text to speech system for Indian Language", International Journal of Advances in Computing and Information Technology ISSN 2277-9140 April 2012. 
[4] D.Sasirekha, E.chandra," Text to Speech:A Simple Turorial", International Journal of Soft Computing and Engineering(IJSCE),ISSN:2231-2307,Volume-2,Issue1,March 2012.

[5] Mahwash Ahmed,Shibli Nisar,"Text-to-Speech using Phoneme Concatenation", International Journal of Scientific Engineering and Technology,Vol 3,Feb 2014.

[6] Allum Mousa,"Voice Conversion Using Pitch shifting algorithm by time stretching with PSOLA and ReSampling",Journal of Electrical Engineering Vol.61.No1,2010.

[7] JodoP.Cabra,LuisC.Oliveria,"Pitch-Synchronous TimeScaling for Prodosic and VoiceQuality bhaTransformations",INTESPEECH 2005.

[8] R.Muralishankar,A.G.Ramakrishana and P.Prathibha, "Modification of Pitch using DCT in the Source Domain",Elsevier-speech communication,vol-42,Feb 2004.

[9] Ulrich Germann,"An Iterative Approach to Pitchmarking of speech signals without Electroglottographic Data,CiteSeer 5M,2006
[10] H.Hussien,M.Wolff,O.Jokisch,F.Duckhorn,G.Strecha and R.Hoffmann,"A Hybrid Speech Signal Based Algorithm for Ptich Marking Using Finite State Machines,INTERSPEECH 2008.

[11] Anant Bhatt,"A PSOLA based Apporach for Voice Morphing",IJDACR,Feb-2015

[12] Kavita Waghmare, Reena H. Chaudhari, Bharti W. Gawali, "Accent identification using MFCC for Hindi Language", Advances in Computational Research, Volume 7, Issue 1, 23 January 2015.

[13] Reena H. Chaudhari, Kavita Waghmare, Bharti W. Gawali, "Accent Recognition using MFCC and LPC with Acoustic Features", International Journal of Innovative Research in Computer and Communication Engineering, Vol. 3, Issue 3, 9 March 2015.

[14] Sangramsing Kayte, Kavita Waghmare, Dr. Bharti Gawali "Marathi Speech Synthesis: A review" International Journal on Recent and Innovation Trends in Computing and Communication ISSN: 2321-8169 Volume: 3 Issue: 63708 - 3711, 24 June 2015 (Impact Factor 5.837 